\title{
Using crowdsourced imagery to detect cultural ecosystem services: a case study in South Wales, UK
}

\author{
Gianfranco Gliozzo $^{1,2}$, Nathalie Pettorelli $^{2}$ and Mordechai (Muki) Haklav ${ }^{1}$
}

\begin{abstract}
Within ecological research and environmental management, there is currently a focus on demonstrating the links between human well-being and wildlife conservation. Within this framework, there is a clear interest in better understanding how and why people value certain places over others. We introduce a new method that measures cultural preferences by exploring the potential of multiple online georeferenced digital photograph collections. Using ecological and social considerations, our study contributes to the detection of places that provide cultural ecosystem services. The degree of appreciation of a specific place is derived from the number of people taking and sharing pictures of it. The sequence of decisions and actions taken to share a digital picture of a given place includes the effort to travel to the place, the willingness to take a picture, the decision to geolocate the picture, and the action of sharing it through the Internet. Hence, the social activity of sharing pictures leaves digital proxies of spatial preferences, with people sharing specific photos considering the depicted place not only "worth visiting" but also "worth sharing visually." Using South Wales as a case study, we demonstrate how the proposed methodology can help identify key geographic features of high cultural value. These results highlight how the inclusion of geographical user-generated content, also known as volunteered geographic information, can be very effective in addressing some of the current priorities in conservation. Indeed, the detection of the most appreciated nonurban areas could be used for better prioritization, planning, and management.
\end{abstract}

Key Words: crowdsourcing; cultural ecosystem services; environmental spaces detection; online imagery; social preferences; spatial analysis; volunteered geographic information (VGI)

\section{INTRODUCTION}

The Millennium Ecosystem Assessment (MEA 2005) focused on an anthropocentric valuation of nature, with a view to developing a framework for accounting for nature and the benefits it provides to humans. The concept of ecosystem services (ES) is widely used in the MEA to describe all aspects of the natural world that contribute directly to the enhancement of human well-being. The definition of ES includes the health and well-being benefits that humans derive from nature. These benefits include: "provisioning services such as food, water, timber, and fiber; regulating services that affect climate, floods, disease, wastes, and water quality; cultural services that provide recreational, aesthetic, and spiritual benefits; and supporting services such as soil formation, photosynthesis, and nutrient cycling" (MEA 2005:v). The ES approach has facilitated interactions between natural scientists, economists, planners, and decision makers using an economicutilitarian perspective (Carpenter et al. 2009). The broader paradigm embraces concepts that fall outside the disciplinary boundaries of natural and environmental sciences, where the focus is on biophysical elements. The ES approach implies a source or a provision point of the benefit, a flow, and a receptor or beneficiary area where the benefits are realized. The shape and strengths of the spatial relationships among these three elements can differ widely (Fisher et al. 2009, Haines-Young and Potschin 2009) and are the main focus of this paper.

\section{Aims and objectives}

Our aim is to demonstrate that online photographic georeferenced user-generated content can be used to detect people's attachment to specific places in nonurban areas. We first introduce the overall paradigm behind the present study and demonstrate the need to open up ecological research to new data sets that are emerging through the Internet to fill a gap in the analysis of social-ecological systems. Similar studies have previously highlighted the opportunities offered by social media to investigate spatial preferences. Combining data from different photo-sharing websites helped us identify the existence of different communities with different habits. Spatial clusters of shared pictures were compared with the locations of ecological and cultural features. From a spatial perspective, the considered methodology allowed us to detect places that people like. From a temporal perspective, shared pictures provide access to real-time information, in contrast to that available from longitudinal surveys.

\section{Cultural ecosystem services}

The most anthropocentric ES are cultural ES (CES), which relate to human immaterial engagement with nature. The relationship between CES and biophysical elements is weak; therefore, preference-based valuation approaches are favored over those based on biophysical elements (Pascual et al. 2010). Nonconsumptive use of natural resources also characterizes CES (MEA 2003). This implies a rather different way of representing the spatial relationship between source flow and receptor. More specifically, the flow can be immaterial in terms of information (Bagstad et al. 2013a:118) or material in that users move toward places they perceive as worth visiting (Costanza 2008). ES that are characterized by biophysical elements such as amount of water, nutrients in soil, temperature, and moisture are measurable in a straightforward way. CES are more difficult to quantify because they are a collection of human cultural perceptions that have no physical component. Nonetheless, material elements trigger such perceptions. Estimation methodologies rely mainly on proxies. Fluxes, numbers of visits, and expenditure by tourists are the quantifiable elements used to measure the effects of tourism (Ghermandi et al. 2011, Bateman et al. 2013).

In current practice, the investigation of CES has implied the integration of landscape ecology, landscape aesthetics, social sciences, and environmental or natural sciences (Schaich et al. 
2010, Bagstad et al. 2013b, Hernández-Morcillo et al. 2013, Plieninger et al. 2013). Surveys have provided the spatial extent and location of places, and the precise identification of places has followed the interpretation of descriptions. This has hindered the ability to locate these places accurately. Some studies have investigated CES along with other ES, analyzing trade-offs. Those results remain heavily dependent on long-lasting traditions and on the cooperation of heterogeneous and complex research teams, as in Bateman et al. (2013). Such approaches strongly depend on the methodologies and data needed for both natural and social sciences. Moreover, the delimitation of a spatial entity from textual descriptions can be inaccurate. While there is a strong focus on outreach to a wider audience, this happens rarely because of the use of technical or disciplinary vocabularies and approaches.

\section{Mapping cultural ecosystem services}

Here, we focus on the possibility of mapping the spatial extent of CES. The UK National Ecosystem Assessment (UK-NEA 2011, 2014) used the term "environmental spaces" to denote the spatial extent of CES. Studies of CES vary widely in terms of spatial analysis and mapping techniques. Ambrose-Oji and Pagella (2012), while focusing on the assessment of woodlands, made a very clear analysis that considered spatial aspects in a way that can be used in other CES analysis. Most of the studies mentioned by Ambrose-Oji and Pagella (2012) deal with a combination of ES rather than CES only. Here, receptors might never have had any physical connections to the ecosystem that ignited their cultural benefit. Therefore, Ambrose-Oji and Pagella (2012) referred to the "ecosystem service footprint," which is not a unique, well-bounded spatial entity, but rather, its shape and extent depend on stakeholders' spatial position, education, and preferences. People who experience the aesthetic enjoyment associated with a woodland live in its vicinity, but this enjoyment is also experienced by those who are willing to move toward the woodland and by people accessing representations of the woodland through the media. Therefore, we can consider that videos, pictures, and even stories and legends in which woodland plays a role contribute to the cultural ecosystem footprint. Two examples of this type of weak interaction between the receptors and physical source of CES are Sherwood Forest and Jerusalem.

One of the main conclusions of Ambrose-Oji and Pagella (2012), as well as of UK-NEA (2014), is that the most appropriate methodologies with which to derive the spatial extent of CES are participatory mapping techniques. Participation might also include a broad range of stakeholders, avoiding focusing on physical proximity as a way to measure the cultural impact of ecosystems. Ambrose-Oji and Pagella (2012) also underlined the inadequacy of land-use change or census units to map ES. Pagella and Sinclair (2014) reviewed ES mapping techniques, comparing 50 published studies in which the importance of land-use change in agricultural land was reported. Among these studies, few explicitly dealt with CES, mainly covering the stock of natural resources in which the services originated. Pagella and Sinclair (2014) found a very limited number of studies analyzing flows and stakeholders. They found that recreation and tourism are the most often mentioned CES. The mapping effort not only relied mainly on analysis units that were hardly suitable for the analysis of ES, but also lacked an assessment of uncertainty when dealing with the boundary of cultural entities.
Bateman et al. (2013) performed an evaluation of the influence of ES-generated values through the creation of six different scenarios of land-use change up to the year 2060. Their study stressed the importance of ES-aware planning decisions in increasing the overall values for ES when the evaluation embraces several ES. The design of the scenarios took into account the effects of climate change. The study provided outcomes that were very clear and were presented using maps that covered the whole $\mathrm{UK}$, with a spatial resolution of $2 \mathrm{~km}^{2}$. The detection of spatial entities was not the aim of these maps, which were the geographical support in combining different levels of spatial information to understand the influence of locality on overall policies. The only cultural aspect considered was recreation.

The conjunction of census, transportation-network analysis, and the Monitor of Engagement with the Natural Environment (MENE) survey (Natural England 2010) provided the inputs for Bateman et al.'s (2013) evaluation. The creation of a tripgeneration function relied on the spatial resolution of Lower Layer Super Output Area (LSOA) census units. LSOAs are geographic areas achieved by aggregating smaller census units with populations of between 1000 and 1500 , but the use of census units causes a bias in spatial resolution. Census units tend to be smaller and more precise in more densely populated urban areas. Moreover, the design of census units is based only on number of inhabitants, number of households, and socioeconomic homogeneity (Cockings et al. 2011); therefore, this tessellation ignores environmental aspects. For less densely populated areas, LSOAs can include areas larger than the minimum spatial resolution used in the study cited.

Therefore, as noted by Pagella and Sinclair (2014), this mapping effort cannot be used to define the extent of environmental spaces for two main reasons: the use of census units for the analysis, and the use of the MENE survey to locate recreational areas as interpreted by the interviewer. Question 7 of the MENE survey (Natural England 2010:12-13) is devoted to the geocoding of the destination of the visit, and a place-name gazetteer supported this choice. There was no analysis of the flux of the benefit, only the flux of beneficiaries. As a result, the structured analysis stressed the role played by recreational areas that were located closer to large, urbanized areas, leading to the conclusion that "land use changes yield larger recreational value impacts when they occur near to populations as opposed to in more remote locations" (Bateman et. al 2013: supplementary material:16). The UK-NEA also developed its scenarios and indicators using the MENE and census output areas (Church et al. 2014, UK-NEA 2014). Bagstad et al. (2013a) proposed an alternative model of the spatial components and the relationships among them for ES. Using artificial intelligence, Bagstad et al. (2013a) distinguished between provisional and preventive ES, and attempted to include competition among usage areas. Because of the specific features that characterize CES, some of these innovations have limited influence for mapping CES. Bagstad et al. (2013a) suggested personal stories and experiences as one of the factors that the system is unlikely to include but that contribute greatly to the detection of CES.

\section{Actions as proxies of preferences}

Participatory mapping and interdisciplinary approaches are at present the two main ways to detect the spatial extent of CES. In 
relation to participatory mapping, receptors are involved in a process with researchers. An interdisciplinary approach often implies the combination of two sources of information: a survey of hundreds of households, and spatial and network analysis using a geographic information system (GIS). Here, we offer another way to detect engagement with a specific environment. The methodology is based on the assumption that one can consider actions undertaken by people as consequences of their preferences because "the true social value of non-marketed ecosystem services depends on the ways that services are used by different stakeholders" (Carpenter et al. 2009:1308).

In Church et al. (2014), the mutual interaction between environmental spaces and cultural practices gives rise to CES. Cultural practices are the activities that relate people to the natural world. Accordingly, we assume that cultural attachment to places motivates people's actions; we can follow the digital traces left by these actions. Bieling and Plieninger (2012) analyzed CES through their material manifestations in landscapes. This work needed extensive fieldwork to record the physical traces of activities for nonmaterial purposes. Among the manifestations, the presence of hiking trails, benches, subsistence gardens (allotments), and memorial plaques evidenced people's pleasure in the surrounding environment, and its enjoyment or symbolic value. Similarly, we assume that people go to specific places, and then, if they like them, share this enjoyment through the Internet, for example, by uploading pictures or talking online with friends. The traceable actions evidence not only the willingness to visit, but also the willingness and inspiration to share. Some of these actions are the result of a sequence of individual decisions; for instance, the action of going to a place, taking pictures, and sharing them is a sequence of three decisions. Taking advantage of Internet tools makes some actions and decisions easy to undertake.

Cultural engagement is inherently a concept that is loosely bounded spatially. Casalegno et al. (2013) attempted the detection of CES at a landscape level through the density of contributors to a photo-sharing website. They analyzed the relevance of Panoramio (http://www.panoramio.com) pictures to evaluate the aesthetic value of landscapes in Cornwall, UK. Their main aim was to analyze the trade-offs with other ES. Their metric was based on the number of photographers for each $1 \mathrm{~km}^{2}$ area. Wood et al. (2013) used pictures from Flickr (http://flickr.com) to evaluate visitation in 836 predetermined cultural and touristic sites worldwide. In another use of Flickr, Richards and Friess (2015) focused on a small-scale analysis in a park, developing the spatial analysis further to include the analysis of environments and focal points. Tenerelli et al. (2016) used the number of pictures shared on Panoramio and Flickr to apply a geographical weighted regression to derive CES. Kachkaev and Wood (unpublished manuscripts) created a leisure pedestrian navigation system eliciting people's preferences from a blend of four online photosharing services.

Here, we follow a path that integrates the aforementioned studies at a regional level. We do not focus on already identified spatial units, but instead, embrace a wider perspective: a social-ecological approach that goes beyond the concept of enclosed conservation areas as in Palomo et al. (2014). We broaden these methodologies and suggest some improvements.

\section{Georeferenced crowdsourced information and places}

The advent of Web 2.0 (O'Reilly 2005) enhanced the possibility of sharing activities socially. Through crowdsourcing (Howe 2006), people have been enabled to contribute massively to projects performing atomized tasks. Some Web 2.0 applications provide the possibility of adding location to the information produced, meaning that this information can be visualized on a map. Crowdsourced imagery is diverse and heterogeneous because the availability of application programming interfaces (APIs) enables the easy downloading of metadata about pictures, as well as the pictures themselves. More interestingly, APIs allow the downloading of users' registration nicknames, comments, and tags that, together with the time and place associated with the pictures, have allowed some studies to focus on users' behavior and preferences. Therefore, photo-sharing websites are a suitable source of information for mapping people's preferences among landscapes and natural environments.

Several studies have used photo-sharing websites with different purposes. Nov et al. (2010) analyzed the dynamics of photosharing communities. They underlined the fact that a sense of belonging to a community, supported by the social-networking functionalities of every application, boosted participants' performances in terms of contribution. Antoniou et al. (2010) aimed to evaluate the role of photo-sharing websites as a source of geographical information. An interesting discovery of their study was as follows: "Spatially speaking, the users are not interested in the small, relatively unpopular, niches of space but focus on the mainstream places" (Antoniou et al. 2010:108).

Following this definition, we assume that the most popular areas are those where more people take pictures, subsequently sharing them online. Users behave selectively and tend to share information regarding specific locations. We assume that this is an expression of their preferences among places. Antoniou et al. 's (2010) evaluation of pictures against a hypothetical isotropic (spatially even) distribution demonstrated that the real behavior of contributors was characterized by a strongly unequal distribution in which the density and clusters of pictures and users revealed people's preferences for places. Girardin et al. (2008) also used this assumption. They analyzed the patterns of geolocated pictures in close proximity to tourist attractions in the province of Florence, Italy. They also underlined the existence of hotspots, and then detected the digital footprints of tourists as they traveled in Italy. Similarly, Kisilevich et al. (2010) conducted their analysis assuming the qualitative derivation of spatial preferences from the quantitative spatial density of pictures shared online. They examined the attractiveness of places by comparing two photosharing websites and an online recommendation system for tourism. Kisilevich et al. (2010) applied the analysis of spatial patterns from photo-sharing websites for only urban environments. It is also an example of the integration of diverse sources of information.

Similarly, Kachkaev and Wood (unpublished manuscripts) applied their methodology to an urban-focused project. Their study, alongside those of Li et al. (2013) and Antoniou et al. (2010), deduced that similar Web 2.0 applications implied different target populations and hence different behaviors. Urban centrality was the target of another qualitative evaluation based on the density of pictures shared online (Hollenstein and Purves 2010). 
Casalegno et al. (2013), Richards and Friess (2015), and Tenerelli et al. (2016) made the only attempts at explicitly targeting the detection of CES through a photo-sharing application. We therefore conclude that there is a rising number of studies that use photo-sharing applications to detect spatial preferences.

\section{Problem statement and research questions}

At present, the detection of CES has received marginal attention (Ambrose-Oji and Pagella 2012) and, when it has been performed, relies only on specific assumptions and mainly targeted recreation and tourism flows (Maes et al. 2012, Milcu et al. 2013, Pagella and Sinclair 2014). Here, we attempted to address the detection of CES using the locations of digital photographs that are shared online through three different platforms. Each platform has a specific character, scope, and supporting community. We drew from different communities that have the fewest characteristics in common in terms of taking and sharing geolocated pictures. The combination of these different applications helped to reduce bias among technology-savvy communities, as identified by Li et al. (2013). We addressed the lack of established and effective methodologies for detecting, measuring, and accounting for CES. In particular, we asked the following questions: Do the different photo-sharing platforms behave spatially similarly? Are there any recognizable spatial patterns, trends, or hotspots in online shared imagery? Are any such patterns or hotspots located only in urban environments? When patterns or hotspots are located outside of urban environments, are they related to some natural or cultural feature? Are such patterns or hotspots located only in designated or protected areas? By addressing these questions, we aimed to assess the suitability of our methodology for assessing CES.

\section{MATERIALS AND METHODOLOGY}

\section{Data sets}

We used the online photo-sharing applications Panoramio, Flickr, and Geograph. For such applications, geographic location is either explicitly requested for every image or is a complementary tag for the photo collection. The former is therefore defined as being explicitly geographic (Panoramio and Geograph), whereas the latter is implicitly geographic (Flickr). These photo-sharing applications have some common characteristics. The first is the availability of an API that allows the use and integration of pictures, data, and metadata (comments, tags, and "likes") shared online by users. A second common characteristic is that all of the applications require users to be registered.

Flickr was launched in 2004 with the purpose of sharing and storing photos online. The geographic component provides added value to the sharing of pictures. Hence, geolocation can be quite inaccurate. For instance, in the study area, we found an entire photo album regarding a touristic town geolocated on only one point.

Panoramio was created in 2005 and was explicitly intended for sharing photos of landscapes. Google acquired this service in 2007 and is the main provider of geolocated pictures overlaid on Google mapping services such as Google maps and Google Earth. As witnessed in community discussions, some users are motivated to contribute because of the global visibility of their pictures. A very active community not only contributes to the collection but also creates online events and contests.
The Geograph Britain and Ireland project (http://www.geograph. org.uk/) began in 2005. Geograph aims to collect geographically representative photographs and information for every squarekilometer of Great Britain and Ireland. The scope is explicitly geographic, and the overall idea is to cover the whole British Isles. Contributors choose to post pictures aiming both to provide aesthetic pleasure and to try to cover all of the territory. Geograph encourages multiple pictures for the same $1 \mathrm{~km}^{2}$ grid unit, and also for smaller $100 \mathrm{~m}^{2}$ grid units. Participants are incentivized with games and leaderboards.

\section{Methodology}

We used a GIS to verify whether these photo-sharing applications are suitable sources of information from which to infer the location of environmental spaces. The methodology used several tools applied in exploratory spatial data analysis based on quadrat counts (de Smith et al. 2007). The main methodological references for the analysis of photo-sharing applications are three studies. First, Kisilevich et al. (2010) used one approach with two different types of baseline data, Flickr and Panoramio. Second, Casalegno et al. (2013) used only Panoramio data and demonstrated the clustering of Panoramio's imagery in specific hotspots. Third, Tenerelli et al. (2016) applied a quadrat count over the number of pictures shared on Flickr and Panoramio.

In contrast to Kisilevich et al.'s (2010) study, which focused on temporal patterns, we examined spatial patterns. After a preliminary analysis of data, we decided to focus on the number of users (as did Girardin et al. 2008, Kisilevich et al. 2010, Casalegno et al. 2013, and Kachkaev and Wood, unpublished manuscripts), rather than the numbers of pictures (as did Antoniou et al. 2010, Richards and Freiss 2015, and Tenerelli et al. 2016). Some individuals share many pictures of an area in relation to a specific interest that is not related to the natural environment; therefore, an approach based on the density of pictures can be misleading in drawing conclusions. For example, around Swansea Airport, there are many pictures from one user, who is passionate about plane-spotting.

Because other studies have already examined urban areas, we focused on nonurban environments. Extending the work of Casalegno et al. (2013), we included a wider spectrum of applications, as well as broadening the analysis to overcome the strong coupling that occurs between one application and its users. This was in accordance with the outcomes of studies focused mainly on urban areas (e.g., Antoniou et al. 2010; Kachkaev and Wood, unpublished manuscripts). The locational information on pictures was collected in August 2015 using APIs and data dumps and was then imported into a spatially enabled database. A spatial query then counted the number of individual users contributing to each of the applications for every $1 \mathrm{~km}^{2}$ of the British National Grid (BNG).

We considered the number of users sharing pictures on the three platforms, and for every individual grid unit, as the main proxy for cultural attachment to the particular territory. To assess how behavior differed by platform, we compared by grid unit the ratio of users to the total number of users for each platform.

To assess spatial autocorrelation, we first derived the global Moran's $I$. To detect the existence of spatial clusters, we used the 
local Moran's $I$. These two steps were also used by RaudseppHearne et al. (2010), Casalegno et al. (2013), and Plieninger et al. (2013). We focused on the areas classified as nonurban according to the definition used in the second stage of the typology produced by the Organisation for Economic Cooperation and Development and by Eurostat (Dijkstra and Poelman 2014). The classification was based on population counts in each grid unit and in the sum of the population of neighboring grid units.

To apply the methodology to select nonurban environments, we needed a population map of the area based on $1 \mathrm{~km}^{2}$ grid units. We derived this from the online tool developed for the Population 24/7 project (http://www.osgl.soton.ac.uk/data/pop247/, obtained on 24 March 2014 while it was hosted by UK Data Service). The information available there for a grid unit of $200 \mathrm{~m}^{2}$ was aggregated to match the $1 \mathrm{~km}^{2}$ unit of the BNG. Then, we applied the methodology to derive urban clusters, as described by Dijkstra and Poelman (2014). The resulting urban areas greatly overlap those obtained by the GIS of the Commission (https://circabc. europa.eu/sd/a/a932d937-82fe-48b6-9c14-1d549ac494f3/

URB CLST 2006.zip) using a different $1 \mathrm{~km}^{2}$ gridded population (Gallego 2010). The resulting nonurban grid units are the focus of our study.

\section{Study area}

The study area of approximately 800,000 ha is characterized by diverse environments. Located in South Wales, UK (Fig. 1), the study area covers, from north to south, the Brecon Beacons National Park in Powys to the coastline facing the Bristol Channel (Fig. 2). West to east, it stretches from the delimitation of the Pembrokeshire Coast National Park to the Wales-England border. Within the wider case-study area, there is a broad range of landscape habitats, according to Scott's (2002) classification. The southerly part of the study area is characterized by diffuse urbanization, with the main urbanized areas around Cardiff, Newport, and Swansea. There is linear urbanization along roads that follow the natural valleys and watercourses toward the Brecon Beacons area from the coastline. According to the UK 2011 census, $>2$ million people live in this area, in 14 counties. There is a diverse mix of designations due to European directives and national and local legislation. These designations include a National Park, Sites of Special Scientific Interest (SSSIs), Special Areas of Conservation, Special Protection Areas (SPAs), Wetlands of International Importance, National Nature Reserves (NNRs), Marine Nature Reserves, Areas of Outstanding Natural Beauty (AONBs), Heritage Coasts, Biosphere Reserves, Biogenetic Reserves, and Local Nature Reserves. Descriptions of these designations are provided by the Joint Nature Conservation Committee (http://jncc.defra.gov.uk/page-1527).

The designated and protected areas are mainly concentrated in the northern part of the study area and along the coastline, where the intricacy of designations leads to overlaps, especially in the Gower Peninsula in the west, across the border between the counties of Swansea and Carmarthenshire. The delta of the River Loughor in the southwest and the surrounding areas have several overlapping designations. Hence, the study area offers a variety of environments for our study, with access to natural parks and natural reserves being relatively easy.
Fig. 1. Location of the South Wales study area in the United Kingdom.

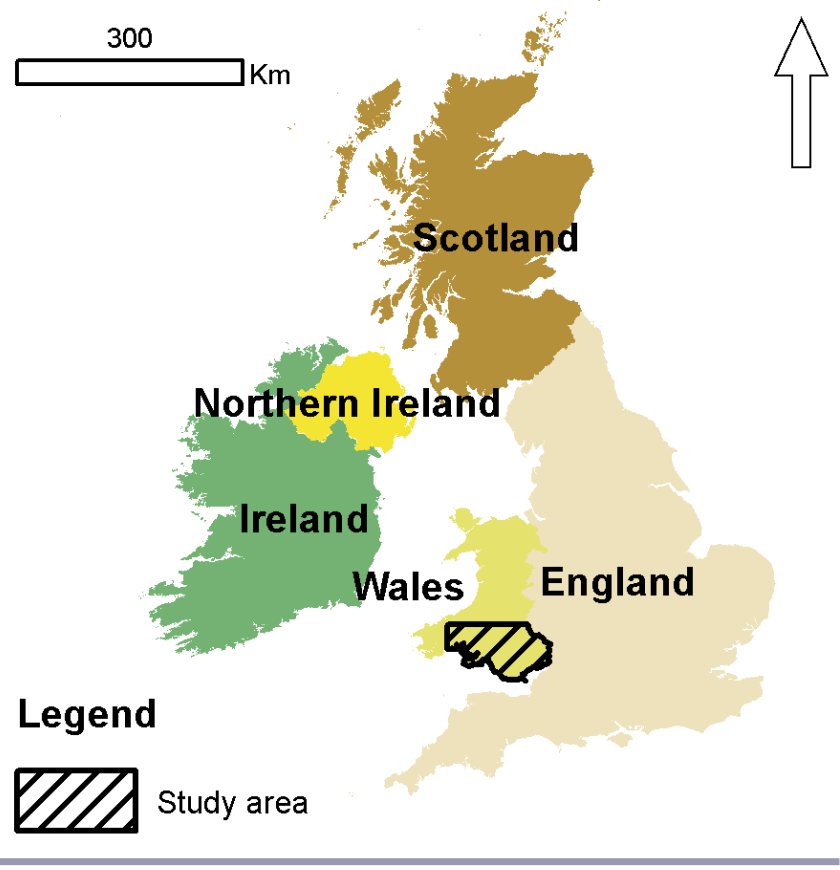

Statistics of resident population and distribution of contributors Our work used spatial units that were not designed around population or social thresholds: an isotropic tessellation based on 7255 BNG units. For the detection of environmental spaces, we then considered the relationship between the number of users that took and posted pictures in the same nonurban grid unit. We then analyzed in more detail 6330 nonurban grid units. Proximity and accessibility characterize CES, as does the movement of the receptor toward the area (Costanza 2008). If people did not move to pursue cultural enjoyment, we would have found only pictures shared in the urban grid units, but we in fact found that people share pictures from nonurban areas. Therefore, we have an indication of the phenomenon and a measure of its magnitude for specific areas. Only 925 grid units $(\sim 14 \%$ of the total) are classified as urban.

\section{RESULTS}

\section{Global statistics}

By analyzing the spatial distribution of contributors, we observed the movement of people from urban to nonurban areas when they take and share pictures. These people are behaving as receptors of the CES. We then considered the number of users of the three photo-sharing platforms, focusing on the distinction between urban and nonurban grid units. The Moran's I global spatial autocorrelation index, calculated over the distribution of total users for every grid unit $(I=0.0651, P=0.001)$, reveals that there is $<1 \%$ probability that the autocorrelation has been generated by a random distribution. There are clusters of grids with elevated number of contributors in both urban and nonurban areas. In general, there are several areas where the aggregation of contributors to photo-sharing platforms is particularly evident (Fig. 3). 
Fig. 2. Detailed map of the South Wales study area, indicating designated and protected areas and urban areas.

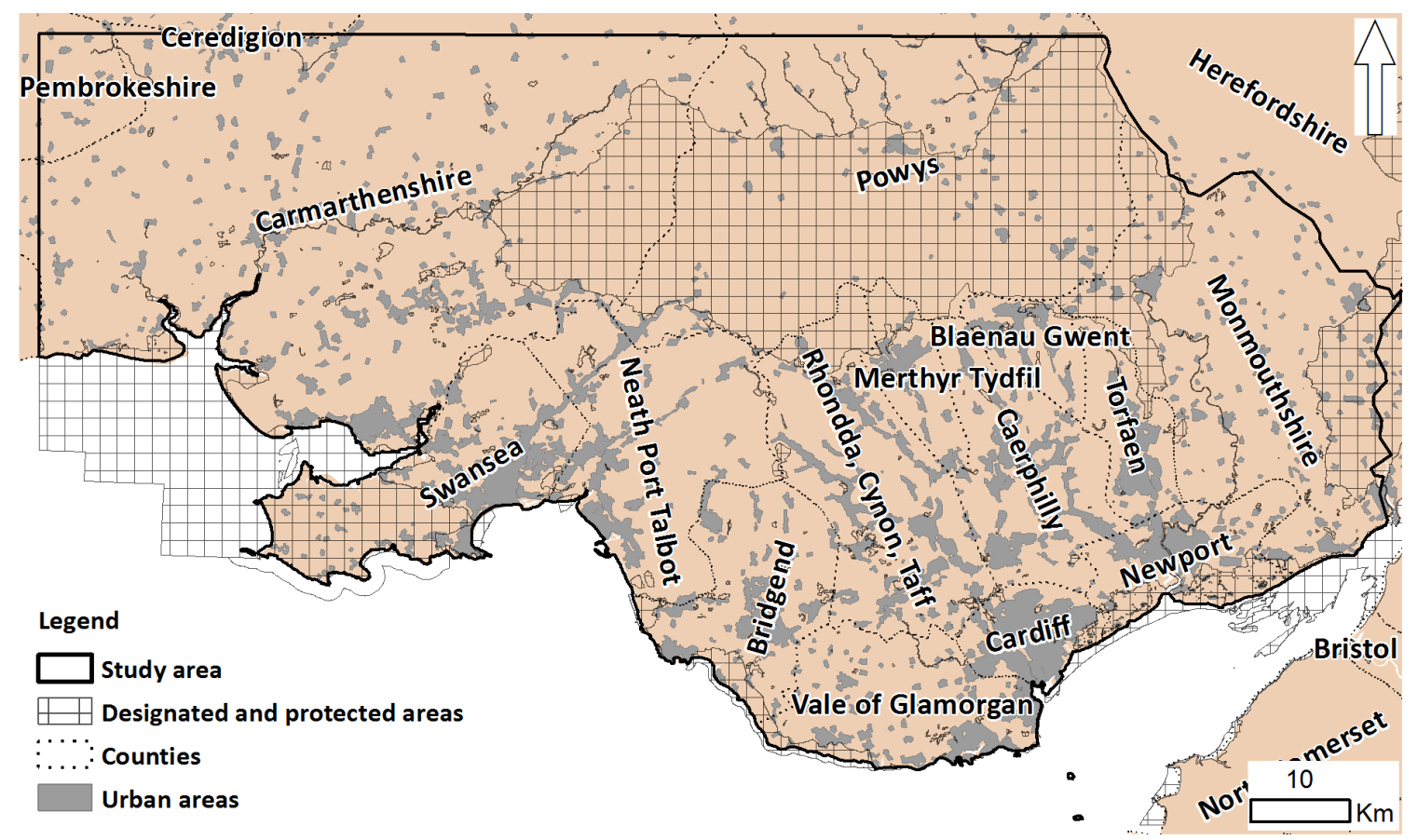

Fig. 3. Map showing the numbers of contributors for all three photo-sharing platforms across all grid units of the study area. Numbers in parentheses in the legend indicate the number of grid units in the specified range.

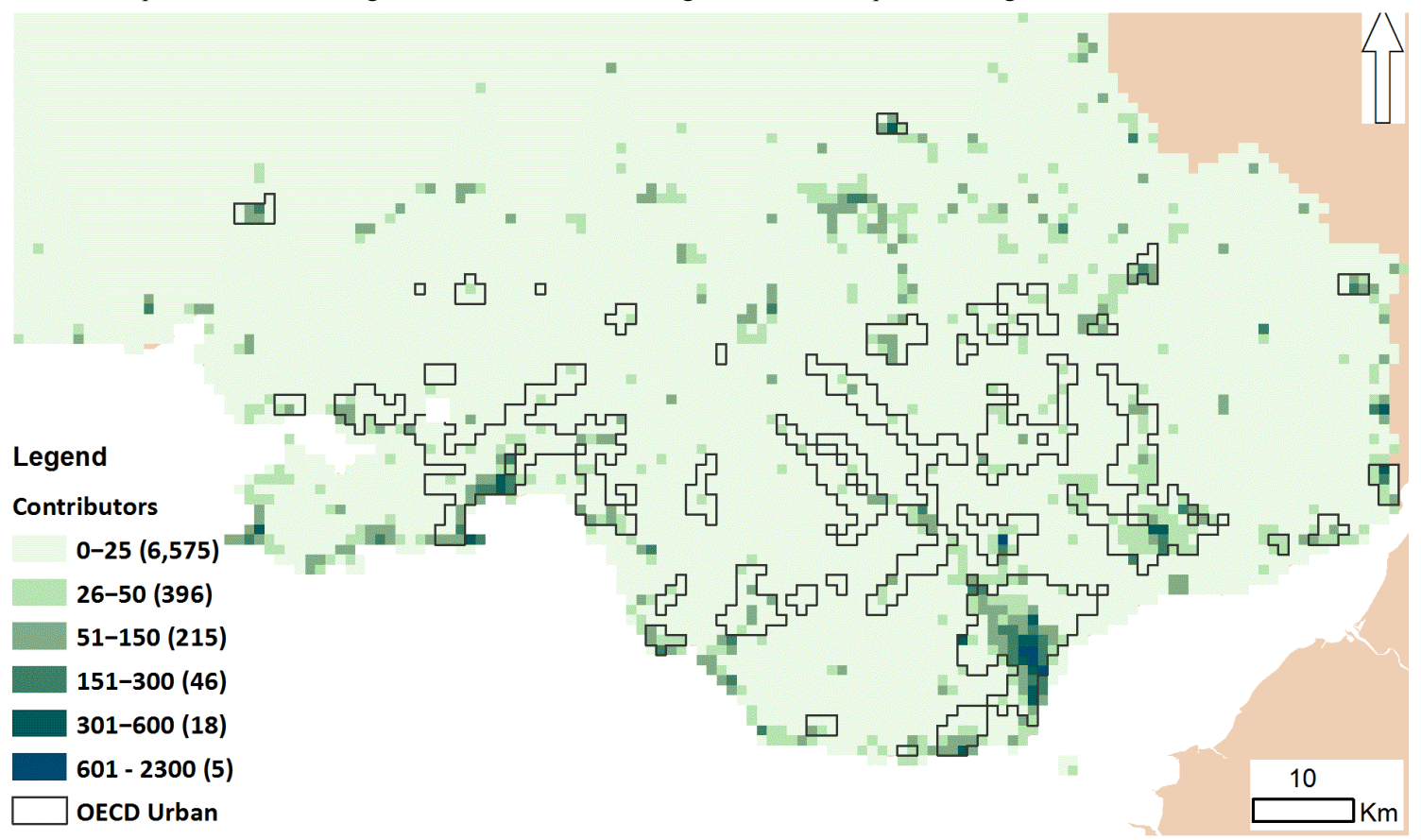


Most clusters of contributors for all three platforms cover urban areas, with a smaller number located in nonurban areas (the vast majority in protected areas; Fig. 3). We derived clusters and outliers, which we comment on in the following sections. Here, we are more interested in the nonurban areas. Of the contributions that we analyzed, none shared pictures from one urban grid unit (the study area had an average of 276 inhabitants $/ \mathrm{km}^{2}$ ). There are 5255 grid units with no resident population but with pictures shared online. Each nonurban grid unit had an average of 9 users sharing pictures, and a maximum of 595 users submitting pictures from the same grid unit.

The total amount of pictures was strongly influenced by the Flickr community, which represented almost $73 \%$ of photos $(444,399$ photos) and $62 \%$ of contributors (9661 contributors). From a geographical point of view, Geograph covers almost $99 \%$ of all the grid units in the area compared to $60 \%$ and $49 \%$ for Flickr and Panoramio, respectively. Geograph's policy to promote spatial coverage using rewards also influences user productivity, with an average contributor providing $>105$ pictures compared to the 46 pictures supplied by Flickr's more numerous but less productive contributors. The most prolific contributor to the Geograph platform $(43,480$ pictures $)$ provided $30 \%$ of the overall platform, which equalled $87 \%$ of all contributors to Panoramio $(49,966$ pictures). The particular behavior of Geograph contributors suggests that the motivations of contributors can be driven by the desire to gain points rather than to share photos of places worth seeing. The behavior of Panoramio users is often included in the range defined by Flickr and Geograph. The proportions of pictures taken in nonurban grid units were $51 \%$ for Panoramio, 55\% for Geograph, and just 31\% for Flickr, yet $87 \%$ of grid units in the study area were nonurban. In general terms, Geograph, with its successful campaign to cover the whole territory, reflects the study area more closely in terms of spatial coverage, but follows Flickr in terms of the quantitative production of pictures. High productivity on the part of some individual contributors can skew the data in terms of the number of pictures and geographic preferences. Therefore, a statistic based on the number of users was more suitable for our study.

\section{Platform specificity}

To compare the three platforms, which have different total numbers of users, we calculated for every grid unit the percentage of users compared with all users contributing to the specific platform. The comparison between Flickr and Panoramio for nonurban areas showed clear coincidence of the two platforms (Fig. 4).

If we omit the two main outliers, Flickr and Panoramio show very similar percentages of users who took pictures in nonurban grid units. These two platforms therefore are similar when compared to Geograph. The relationship between Geograph and Flickr is strongly skewed toward Geograph (Fig. 5). This was as expected because of Geograph's policy, which covers almost $99 \%$ of all grid units, whereas Flickr does not reach $60 \%$ and Panoramio not even $49 \%$. For the nonurban areas, Geograph coverage is closer to $99 \%$, whereas the percentages fall to $54 \%$ and $43 \%$ for Flickr and Panoramio, respectively. This evidences the selectiveness of people using Flickr and Panoramio when dealing with areas worth sharing visually, compared to Geograph users, whose aim is to cover all areas.
Fig. 4. Comparison of the numbers of contributors to Panoramio and Flickr for nonurban grid units.

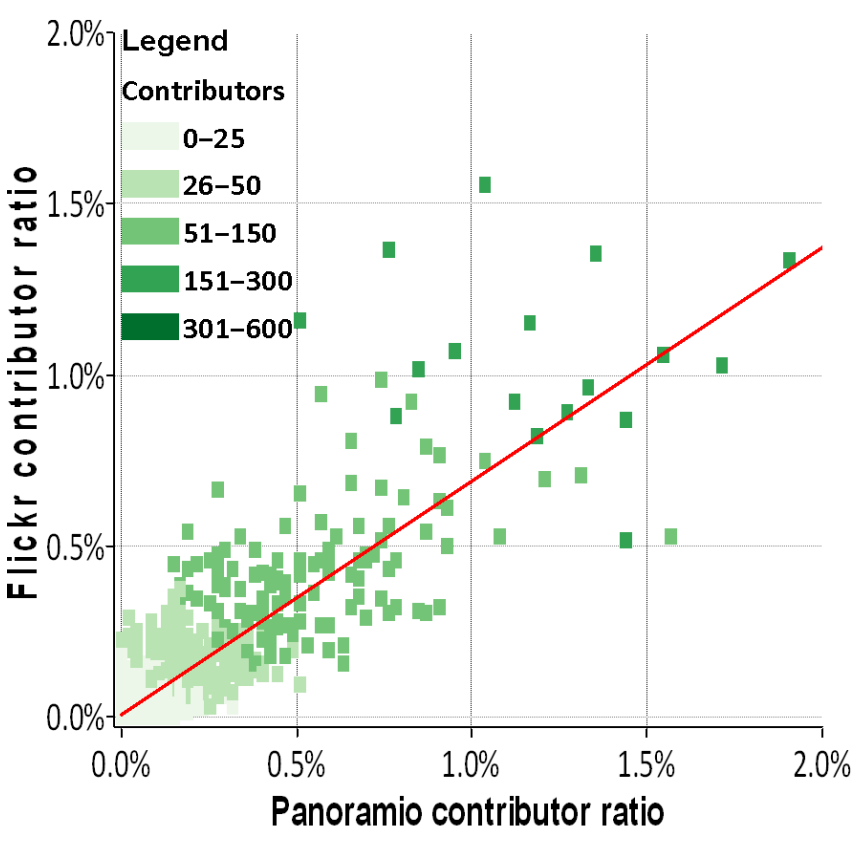

Fig. 5. Comparison of the numbers of contributors to Geograph and Flickr for nonurban grid units.

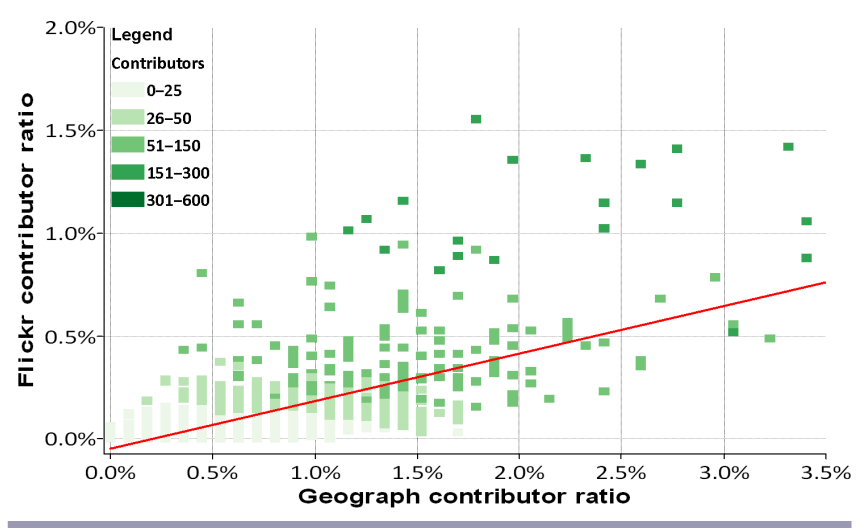

\section{Local spatial statistics}

Spatial trends: hotspots and outliers

To detect spatially statistically significant grid units, such as spatial clusters and outliers, we used Moran's I local indicator of spatial association (LISA; Anselin 1995) as implemented in ArcGIS 10.2.2 spatial statistic tools. This allowed us to find both clusters of grid units with high numbers of contributors and grid units that differed markedly from surrounding grid units. There were 295 grid units with significant local autocorrelation. They can be grouped into 40 spatial clusters of grid units having a high number of contributors, whereas the other 36 grid units are considered individual or outlying because they are surrounded by grid units with lower numbers of contributors. Filtering out 
Fig. 6. Clusters and hotspots, as identified by Moran's I local indicator of spatial association (LISA). Letters indicate clusters of grid units discussed in the text.

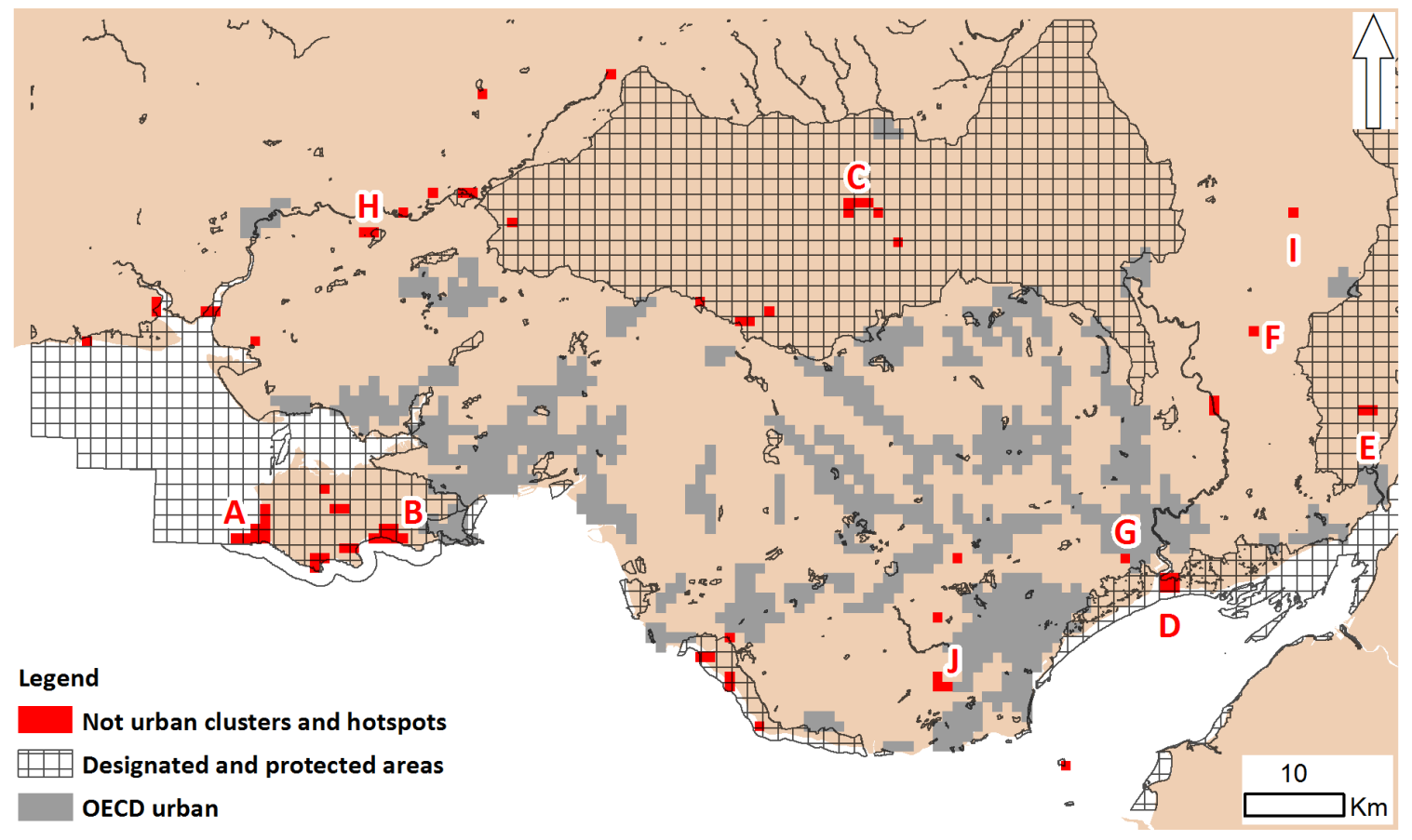

clusters and outliers pertaining to the urban areas resulted in 20 clusters with high values and 17 outliers (isolated grid units characterized by values higher than their surrounding units). Therefore, our second and third research questions about spatial patterns, trends, and hotspots are addressed not only after delimiting spatial clusters but also having found that approximately $45 \%$ of them are nonurban. To answer the last two research questions about patterns or hotspots associated with natural and cultural features, we analyzed the clusters and outliers.

\section{Sites of special photographic interest}

Among all the statistically relevant elements derived using LISA, eight grid units constitute the largest cluster, which partly covers Rhossili Bay on the Gower Peninsula. The most easily accessible part of the bay has the most contributors (Fig. 6, cluster A). In 2014, a popular touristic website ranked the bay as the ninth best beach in the world (TripAdvisor, Top 25 beaches - world, http:// www.tripadvisor.co.uk/TravelersChoice-Beaches-cTop-g1). This cluster is second in terms of the number of pictures and seventh in terms of average users. It includes the second and fifth most popular grid units, the first of which is the most popular grid unit in Panoramio, and the second of which is the most popular grid unit in Geograph. The cluster includes part of the Gower AONB, the Carmarthen Bay SPA, three SSSIs (Gower Coast: Rhossili to Port Eynon; Rhossili Down; and Sluxton Marsh, Whitemoor), and the Gower Coast NNR.

Six grid units constitute the second largest cluster (Fig. 6, cluster B), which covers Three Cliffs Bay (three SSSIs, one AONB, and one NNR). This cluster includes the 14th most popular grid unit.
Two clusters of four grid units are located in two diverse environments. One, which includes the third and tenth most popular grid units, covers the highest peaks of the Brecon Beacons (Fig. 6, cluster C), which give the name to the National Park and the SSSI partially covered by the cluster. This cluster includes the third and tenth most popular grid units. The cluster is situated in the Severn Estuary SSSI and covers the Newport Wetlands SSSI and NNR (Fig. 6, cluster D). A mixture of landscape and closeup pictures similar to those used for environmental observation characterizes this cluster.

Two grid units constitute the most popular cluster (Fig. 6, cluster E). This cluster has the highest average number of users in any platform; it contains the overall most popular grid unit on both Flickr and Geograph, and the second most popular grid unit on Panoramio. This grid unit contains a feature that is cultural in a natural area: Tintern Abbey, in the Wye Valley AONB. It is very close to the River Wye, which has a dedicated SSSI. The remaining grid unit in the cluster owes its popularity to the views over the abbey and the natural area surrounding it.

Looking at outliers, we note that the second most popular statistical element overall, which is also the sixth most popular grid unit, includes the ruins of Raglan Castle (Fig. 6, cluster F). Another outlier is Tredegar House and its gardens, which is the 20th most popular grid unit (Fig. 6, cluster G). The cluster containing the National Botanic Garden of Wales is also a statistical outlier (Fig. 6, cluster H). Both Raglan Castle and Tredegar House are not included in conservation areas, but do constitute cultural heritage. Three kinds of pictures contributed to the success of Tredegar House: those of the house itself; those of the park, with flowers and birds; and those of an annual vintage 
car show, attended by several Flickr users. The grid unit containing Skenfrith Castle and the adjacent church (Fig. 6, cluster I) constitutes a statistically significant outlier that does not include conservation areas.

All of this evidence points to the blending of natural and cultural elements that are considered worth sharing visually. The range spans from predominantly natural features such as coastal landscapes, waterfalls, and open views to predominantly manmade cultural features such as castles, Neolithic dolmens (Fig. 6, cluster J), and National Trust houses. Cultural features are more likely to be included when they form part of conservation areas and have gardens used to host events.

\section{DISCUSSION}

Our study shows that people tend to take and share pictures more readily when they go to specific places; this further confirms the findings of previous studies (Girardin et al. 2008, Antoniou et. al 2010, Casalegno et al. 2013, Tenerelli et al. 2016). The analysis involved several photo-sharing websites to overcome the limitations of a study focused on just one community and one online service. With respect to the research questions, we found that different photo-sharing platforms have different spatial behaviors that can shed light on different types of motivation to participate in the collection and sharing of pictures. Some key hotspots are shared among different applications, and Flickr and Panoramio have quite similar patterns when dealing with nonurban areas. More precisely, we can stress the role of panoramic views, and heritage monuments such as castles and heritage houses with gardens. As we expected, social-ecological couplings occur also outside of urban and designated areas, stressing the role of cultural heritage elements. Although there are different services and communities involved, some areas have been more popular, and arguably, this is an indication that those places are "worth sharing socially" through pictures when visiting them. People express their cultural preferences by moving toward those specific places and by sharing their experience. Therefore, they are playing the double role of receptors as well as reporters of CES.

Photo-sharing services have been characterized as follows: Flickr is significantly more successful than the other platforms in terms of pictures and contributors. Together with pictures related to the surrounding natural environment, photos conveyed there are more focused on human environments and activities such as festivals and events. Panoramio's imagery is more evenly distributed than Flickr's and tends to have an evenly spread coverage that also encompasses more natural areas. Flickr and Panoramio reveal very similar photo-sharing behavior in nonurban areas. In contrast, Geograph covers almost all of the territory and may be a better proxy for accessibility estimations. Nevertheless, for our purposes, some limitations of the Geograph platform may be seen as deriving from the gamified approach that puts emphasis on leaderboards, rewards, and games.

While clusters and hotspots are located both in urban and in nonurban environments, we focused on the importance of nonurban elements. The combination of three factors influences the trends. One element is the presence of accessible views over specific landscapes (peaks and beaches); this forms the basis of larger clusters, with high numbers of contributors. The second element is the presence of historic and picturesque human artifacts such as ruins, castles, and heritage houses. Finally, places organized to stress the role of biodiversity, such as the National Botanic Garden of Wales and the Newport Wetlands visitor center, are characterized by the concentration of pictures that are similar to environmental observations. Very often, we identified a combination of these three elements where events are organized. For example, in Flickr mainly, there was a wide range of pictures taken in the areas around Tredegar House and the Newport Wetlands visitor center, including distant objects and landscapes as well as close-up shots of flowers and insects.

Therefore, the interest of the population in natural features and open spaces is not confined to natural reserves and other designated areas, but is supported by the accessibility and organization of cultural practices. A similar trend characterizes human-made artifacts, the intrinsic nature of which is characterized by a higher degree of accessibility.

In comparison to previous studies, we argue that the use of just one service or one set of geographic tessellation for the analysis can provide some insight. Comparison between different communities is more effective and can cover different aspects of the human experience of open space and nature.

\section{GROUNDED SPECULATION AND CONCLUSION}

Here, we explored the potential of just one of the information components that are handled on photo-sharing websites. From a broader perspective, such websites can be viewed as multifaceted sources of social and spatial information that can be very relevant to CES research and practice. The information bundle provided by the APIs includes several components. Contributors usually post pictures using their nicknames (often a combination of given name and surname) and then share the picture using spatial and temporal information and tags, or even a description of the photo. However, the websites contain several social features such as interest groups and the facility to add "likes," comments, tags, and ratings of pictures. Therefore, several improvements to our study, as well as the identification of complementary streams of research, may flow from this abundant swath of information.

A first degree of analysis could be conducted on the demographic profiling of contributors to find patterns and trends related to variables such as gender, social class, and age in relation to their area of residence (known as geodemographic analysis). Similar geodemographic analysis in the USA demonstrated the importance of analyzing the target population of every form of social media, as stressed by Duggan and Brenner (2013) and Li et al. (2013). Because cultural and social differences strongly influence CES-related preferences (Wood et al. 2013, LópezSantiago et al. 2014, UK-NEA 2014), and engagement with open space and nature is ethnically bounded (Agyeman 1990), we would expect such analysis to yield useful results. The social components of photo-sharing websites provide another level of investigation. Spatial cooccurrence in specific areas can be analyzed, along with digital networking (Cranshaw et al. 2010), through connections, "likes," and ratings. Work in this area looks promising, providing a possible link with applications developed for the social recommendation of places, as in Kisilevich et al. (2010). The influence of social-networking tools on photosharing websites has already been analyzed by Nov et al. (2010). A deeper analysis would improve the understanding of the behavior of contributors in gamified crowdsourcing platforms 
such as Geograph. Some studies take advantage of the textual component included in comments and tags attached to pictures; studies of conceptualizations from crowdsourced information aim to do this. Some studies have derived ontologies and folksonomies (Garduño Freeman 2010) from Flickr tags, "likes," and groups (Hollenstein and Purves 2010).

Our work has demonstrated the potential contribution of crowdsourcing information to ecological research by analyzing three platforms (Flickr, Panoramio, and Geograph) with technological arrangements that similarly support and promote the collection of photos taken by members of the public. The analysis has allowed us to identify CES in South Wales. Focusing on nonurban areas, the three platforms show different photosharing behavior, with Flickr and Panoramio showing almost interchangeable results whereby Flickr stresses more humanmade cultural artifacts. Geograph stresses the same places with different intensity. Knowing the purpose of the originating platform can help in understanding the social-ecological couplings detected. Clusters and hotspots are detected both in urban and nonurban environments. All the nonurban clusters and hotspots are focused on cultural features, either human-made or natural. For all the clusters and hotspots detected, a protection or listing status is already granted for reasons of natural or historical heritage.

Responses to this article can be read online at: http://www.ecologyandsociety.org/issues/responses. $\mathrm{php} / 8436$

\section{Acknowledgments:}

We thank Artemis Skarlatidou for insightful suggestions on earlier versions of the text. The work described here is supported by the UK Research Council through the UCL Centre for Virtual Environments Interaction and Visualisation (VEIV) and the Institute of Zoology (IoZ) of the Zoological Society of London (ZSL). Maps contain Ordinance Survey data, Crown copyright and database rights 2016. Additional data are sourced from third parties, including public sector information licensed under the Open Government Licence v1.0.

\section{LITERATURE CITED}

Agyeman, J. 1990. Black people in a white landscape: social and environmental justice. Built Environment 16(3):232-236. [online] URL: http://www.jstor.org/stable/23286762

Ambrose-Oji, B., and T. Pagella. 2012. Spatial analysis and prioritisation of cultural ecosystem services: a review of methods. Research Report. Forest Research, Farnham, UK. [online] URL: http://www.forestry.gov.uk/pdf/CES_spatial_analysis_tools_review_2102. pdf/SFILE/CES spatial_analysis tools_review_2102.pdf

Anselin, L. 1995. Local indicators of spatial association-LISA. Geographical Analysis 27(2):93-115. http://dx.doi.org/10.1111/ j.1538-4632.1995.tb00338.x

Antoniou, V., J. Morley, and M. Haklay. 2010. Web 2.0 geotagged photos: assessing the spatial dimension of the phenomenon. Geomatica 64(1):99-110.
Bagstad, K. J., G. W. Johnson, B. Voigt, and F. Villa. 2013a. Spatial dynamics of ecosystem service flows: a comprehensive approach to quantifying actual services. Ecosystem Services 4:117-125. http://dx.doi.org/10.1016/j.ecoser.2012.07.012

Bagstad, K. J., D. J. Semmens, S. Waage, and R. Winthrop. $2013 b$. A comparative assessment of decision-support tools for ecosystem services quantification and valuation. Ecosystem Services 5:27-39. http://dx.doi.org/10.1016/j.ecoser.2013.07.004

Bateman, I. J., A. R. Harwood, G. M. Mace, R. T. Watson, D. J. Abson, B. Andrews, A. Binner, A. Crowe, B. H. Day, S. Dugdale, C. Fezzi, J. Foden, D. Hadley, R. Haines-Young, M. Hulme, A. Kontoleon, A. A. Lovett, P. Munday, U. Pascual, J. Paterson, G. Perino, A. Sen, G. Siriwardena, D. van Soest, and M. Termansen. 2013. Bringing ecosystem services into economic decisionmaking: land use in the United Kingdom. Science 341 (6141):45-50. http://dx.doi.org/10.1126/science.1234379

Bieling, C., and T. Plieninger. 2013. Recording manifestations of cultural ecosystem services in the landscape. Landscape Research 38(5):649-667. http://dx.doi.org/10.1080/01426397.2012.691469

Carpenter, S. R., H. A. Mooney, J. Agard, D. Capistrano, R. S. DeFries, S. Díaz, T. Dietz, A. K. Duraiappah, A. Oteng-Yeboah, H. M. Pereira, C. Perrings, W. V. Reid, J. Sarukhan, R. J. Scholes, and A. Whyte. 2009. Science for managing ecosystem services: beyond the Millennium Ecosystem Assessment. Proceedings of the National Academy of Sciences 106(5):1305-1312. http://dx. doi.org/10.1073/pnas.0808772106

Casalegno, S., R. Inger, C. DeSilvey, and K. J. Gaston. 2013. Spatial covariance between aesthetic value and other ecosystem services. Plos One 8(6):e68437. http://dx.doi.org/10.1371/journal. pone. 0068437

Church, A., R. Fish, R. Haines-Young, S. Mourato, J. Tratalos, L. Stapleton, C. Willis, P. Coates, S. Gibbons, C. Leyshon, M. Potschin, N. Ravenscroft, R. Sanchis-Guarner, M. Winter, and J. Kenter. 2014. UK National Ecosystem Assessment follow-on. Work Package Report 5: Cultural ecosystem services and indicators. UNEP-WCMC, LWEC, Cambridge, UK. [online] URL: http:// uknea.unep-wcmc.org/LinkClick.aspx?fileticket $=10 \% 2 \mathrm{fZhq} \% 2 \mathrm{bgwtc} \%$ $\underline{3 \mathrm{~d} \& \text { tabid }=82}$

Cockings, S., A. Harfoot, D. Martin, and D. Hornby. 2011. Maintaining existing zoning systems using automated zonedesign techniques: methods for creating the 2011 census output geographies for England and Wales. Environment and Planning $A$ 43(10):2399-2418. http://dx.doi.org/10.1068/a43601

Costanza, R. 2008. Ecosystem services: multiple classification systems are needed. Biological Conservation 141(2):350-352. http://dx.doi.org/10.1016/j.biocon.2007.12.020

Cranshaw, J., E. Toch, J. Hong, A. Kittur, and N. Sadeh. 2010. Bridging the gap between physical location and online social networks. Pages 119-128 in UbiComp '10 Proceedings of the 12th ACM international conference on ubiquitous computing. ACM, New York, New York, USA. http://dx.doi.org/10.1145/1864349.1864380

de Smith, M. J., M. F. Goodchild, and P. A. Longley. 2007. Geospatial analysis: a comprehensive guide to principles, techniques and software tools. Troubador, Kibworth Beauchamp, UK. 
Dijkstra, L., and H. Poelman. 2014. A harmonised definition of cities and rural areas: the new degree of urbanisation. WP 01/2014. European Commission, Brussels, Belgium. [online] URL: $\underline{\text { http:// }}$ ec.europa.eu/regional_policy/sources/docgener/work/2014_01_new urban. pdf

Duggan, M., and J. Brenner. 2013. The demographics of social media users - 2012. Pew Research Center, Washington, D.C., USA. [online] URL: http://pewinternet.org/ /media//Files/ Reports/2013/PIP SocialMediaUsers.pdf

Fisher, B., R. K. Turner, and P. Morling. 2009. Defining and classifying ecosystem services for decision making. Ecological Economics 68(3):643-653. http://dx.doi.org/10.1016/j. ecolecon.2008.09.014

Gallego, F. J. 2010. A population density grid of the European Union. Population and Environment 31(6):460-473. http://dx.doi. org/10.1007/s11111-010-0108-y

Garduño Freeman, C. 2010. Photosharing on Flickr: intangible heritage and emergent publics. International Journal of Heritage Studies 16(4-5):352-368. http://dx.doi.org/10.1080/13527251003775695

Ghermandi, A., P. A. L. D. Nunes, R. Portela, N. Rao, and S. S. Teelucksingh. 2011. Recreational, cultural and aesthetic services from estuarine and coastal ecosystems. Pages 217-237 in M. van den Belt and R. Costanza, editors. Treatise on estuarine and coastal science. Academic Press, London, UK.

Girardin, F., F. D. Fiore, C. Ratti, and J. Blat. 2008. Leveraging explicitly disclosed location information to understand tourist dynamics: a case study. Journal of Location Based Services 2 (1):41-56. http://dx.doi.org/10.1080/17489720802261138

Haines-Young, R., and M. Potschin. 2009. The links between biodiversity, ecosystem services and human well-being. Pages 110-139 in D. G. Raffaelli and C. L. J. Frid, editors. Ecosystem ecology: anew synthesis. Cambridge University Press, Cambridge, UK. http://dx.doi.org/10.1017/cbo9780511750458.007

Hernández-Morcillo, M., T. Plieninger, and C. Bieling. 2013. An empirical review of cultural ecosystem service indicators. Ecological Indicators 29:434-444. http://dx.doi.org/10.1016/j. ecolind.2013.01.013

Hollenstein, L., and R. Purves. 2010. Exploring place through user-generated content: using Flickr to describe city cores. Journal of Spatial Information Science 1(1):21-48. http://dx.doi. org/10.5311/JOSIS.2010.1.3

Howe, J. 2006. The rise of crowdsourcing. Wired Magazine June 1, 2006. [online] URL: http://www.wired.com/2006/06/crowds/

Kisilevich, S., M. Krstajic, D. Keim, N. Andrienko, and G. Andrienko. 2010. Event-based analysis of people's activities and behavior using Flickr and Panoramio geotagged photo collections. Pages 289-296 in E. Banissi, S. Bertschi, R. Burkhard, J. Counsell, M. Dastbaz, M. Eppler, C. Forsell, G. Grinstein, J. Johansson, M. Jern, F. Khosrowshahi, F. T. Marchese, C. Maple, R. Laing, U. Cvek, M. Trutschl, M. Sarfraz, L. Stuart, A. Ursyn, and T. G. Wyeld, editors. Information visualisation. IEEE Computer Society, Los Alamitos, California, USA. http://dx.doi. org/10.1109/iv.2010.94
Li, L., M. F. Goodchild, and B. Xu. 2013. Spatial, temporal, and socioeconomic patterns in the use of Twitter and Flickr. Cartography and Geographic Information Science 40(2):61-77. http://dx.doi.org/10.1080/15230406.2013.777139

López-Santiago, C. A., E. Oteros-Rozas, B. Martín-López, T. Plieninger, E. González Martín, and J. A. González. 2014. Using visual stimuli to explore the social perceptions of ecosystem services in cultural landscapes: the case of transhumance in Mediterranean Spain. Ecology and Society 19(2):27. http://dx. doi.org/10.5751/es-06401-190227

Maes, J., B. Egoh, L. Willemen, C. Liquete, P. Vihervaara, J. P. Schägner, B. Grizzetti, E. G. Drakou, A. La Notte, G. Zulian, F. Bouraoui, M. L. Paracchini, L. Braat, and G. Bidoglio. 2012. Mapping ecosystem services for policy support and decision making in the European Union. Ecosystem Services 1(1):31-39. http://dx.doi.org/10.1016/j.ecoser.2012.06.004

MEA (Millennium Ecosystem Assessment). 2003. Ecosystems and human well-being: a framework for assessment. Island Press, Washington, D.C., USA. [online] URL: http://pdf.wri.org/ ecosystems human wellbeing.pdf

MEA (Millennium Ecosystem Assessment). 2005. Ecosystems and human well-being: synthesis. Island Press, Washington, D.C., USA. [online] URL: http://www.millenniumassessment.org/ documents/document.356.aspx.pdf

Milcu, A. I., J. Hanspach, D. Abson, and J. Fischer. 2013. Cultural ecosystem services: a literature review and prospects for future research. Ecology and Society 18(3):44. http://dx.doi.org/10.5751/ ES-05790-180344

Natural England. 2010. Monitor of Engagement with the Natural Environment: the national survey on people and the natural environment. Technical Report NECR050. Natural England, Sheffield, UK. [online] URL: http://publications.naturalengland. org.uk/file/75041

Nov, O., M. Naaman, and C. Ye. 2010. Analysis of participation in an online photo-sharing community: a multidimensional perspective. Journal of the American Society for Information Science and Technology 61(3):555-566. http://dx.doi.org/10.1002/ asi. 21278

O'Reilly, T. 2005. What is Web 2.0: design patterns and business models for the next generation of software. O'Reilly Media, Sebastopol, California, USA. [online] URL: http://www.oreilly. com/pub/a/web2/archive/what-is-web-20.html

Pagella, T. F., and F. L. Sinclair. 2014. Development and use of a typology of mapping tools to assess their fitness for supporting management of ecosystem service provision. Landscape Ecology 29(3):383-399. http://dx.doi.org/10.1007/s10980-013-9983-9

Palomo, I., C. Montes, B. Martín-López, J. A. González, M. García-Llorente, P. Alcorlo, and M. R. García Mora. 2014. Incorporating the social-ecological approach in protected areas in the Anthropocene. BioScience 64(3):181-191. http://dx.doi. org/10.1093/biosci/bit033

Pascual, U., R. Muradian, L. Brander, E. Gómez-Baggethun, B. Martín-lópez, M. Verma, P. Armsworth, M. Christie, H. 
Cornelissen, F. Eppink, J. Farley, J. Loomis, L. Pearson, C. Perrings, and S. Polasky. 2010. The economics of valuing ecosystem services and biodiversity. In The economics of ecosystems and biodiversity: the ecological and economic foundations. United Nations Environment Program, Geneva, Switzerland. [online] URL: http://www.teebweb.org/wp-content/ uploads/2013/04/D0-Chapter-5-The-economics-of-valuing-ecosystemservices-and-biodiversity.pdf

Plieninger, T., S. Dijks, E. Oteros-Rozas, and C. Bieling. 2013. Assessing, mapping, and quantifying cultural ecosystem services at community level. Land Use Policy 33:118-129. http://dx.doi. org/10.1016/j.landusepol.2012.12.013

Raudsepp-Hearne, C., G. D. Peterson, and E. M. Bennett. 2010. Ecosystem service bundles for analyzing tradeoffs in diverse landscapes. Proceedings of the National Academy of Sciences 107 (11):5242-5247. http://dx.doi.org/10.1073/pnas.0907284107

Richards, D. R., and D. A. Friess. 2015. A rapid indicator of cultural ecosystem service usage at a fine spatial scale: content analysis of social media photographs. Ecological Indicators 53:187-195. http://dx.doi.org/10.1016/j.ecolind.2015.01.034

Schaich, H., C. Bieling, and T. Plieninger. 2010. Linking ecosystem services with cultural landscape research. GaiaEcological Perspectives for Science and Society 19(4):269-277. [online] URL: http://www.ingentaconnect.com/contentone/oekom/ gaia/2010/00000019/00000004/art00009

Scott, A. 2002. Assessing public perception of landscape: the LANDMAP experience. Landscape Research 27(3):271-295. http://dx.doi.org/10.1080/01426390220149520

Tenerelli, P., U. Demšar, and S. Luque. 2016. Crowdsourcing indicators for cultural ecosystem services: a geographically weighted approach for mountain landscapes. Ecological Indicators 64:237-248. http://dx.doi.org/10.1016/j.ecolind.2015.12.042

UK-NEA (UK National Ecosystem Assessment). 2011. The UK National Ecosystem Assessment: synthesis of the key findings. UNEP-WCMC, Cambridge, UK. [online] URL: http://uknea. unep-wcmc.org/LinkClick.aspx?fileticket=ryEodO1 KG3k $\% 3 \mathrm{~d} \&$ tabid $=82$

UK-NEA (UK National Ecosystem Assessment). 2014. The UK National Ecosystem Assessment: synthesis of the key findings. UNEP-WCMC, LWEC, Cambridge, UK. [online] URL: http:// uknea.unep-wcmc.org/LinkClick.aspx?fileticket $=5 \mathrm{~L} 6 \% 2 \mathrm{fu} \% 2 \mathrm{~b} \%$ 2 frKKA $\% 3 \mathrm{~d} \&$ tabid $=82$

Wood, S. A., A. D. Guerry, J. M. Silver, and M. Lacayo. 2013. Using social media to quantify nature-based tourism and recreation. Scientific Reports 3:2976. http://dx.doi.org/10.1038/ $\underline{\text { srep02976 }}$ 